\title{
Use of Anti-HLA Antibodies to Mask Major Histocompatibility Complex Gene Products on Tumor Cells Can Enhance Susceptibility of These Cells to Lysis by Natural Killer Cells
}

Peter I. Lobo and Clinton E. Spencer

Department of Internal Medicine, University of Virginia School of Medicine, Charlottesville, Virginia 22908

\begin{abstract}
The role of major histocompatibility gene products (i.e., HLA molecules) in rendering tumor cells resistant to natural killer (NK) cell-mediated lysis was investigated by using mouse monoclonal antibodies to bind and mask HLA or non-HLA gene products on the cell membrane of human allogeneic tumor targets. Enhanced lysis of resistant lymphoid and certain other solid tumor cell lines was observed only when monoclonals used reacted to class I and II HiLA molecules but not non-HLA molecules on tumor targets. Enhanced lysis was not due to antibody dependent cellular cytotoxicity or due to an effect of antibody on NK effectors. Of importance, normal autologous and allogeneic human lymphocytes could not be lysed by NK cells despite blast transformation with mitogens or masking of HLA membrane determinants on blasts with monoclonal antibodies. Enhanced lysis, in the presence of antibody to HLA antigens, was not due to increased NK cell binding to tumor targets, but a consequence of enhanced postbinding lysis. Studies using granules obtained from NK cells indicated that masking of HLA antigens did not enhance the susceptibility of tumor targets to cytolysins. Such observations would suggest that HLA antigens on tumor targets inhibit the triggering of effector cells (and release of cytolysins) after recognition and binding of NK cells to target cells.
\end{abstract}

\section{Introduction}

The presence of natural killer (NK) ${ }^{1}$ cells in normal individuals, has led investigators to unravel its normal in vivo significance and, in particular, elucidate mechanisms that render tumor cells susceptible to lysis by such cells. Unlike other forms of immune-mediated lysis, and hence intriguing, is the observation that NK-mediated lysis of susceptible tumor targets will occur in the absence of prior immunization or sensitization (1). It is possible, therefore, that NK mediated lysis may subserve a more primordial host defense against malignancy as has been suggested (2).

Address reprint requests to Dr. Lobo, Department of Internal Medicine, University of Virginia School of Medicine, Charlottesville, VA 22908.

Received for publication 11 January 1988 and in revised form 6 July 1988.

1. Abbreviations used in this paper: $\mathrm{ADCC}$, antibody dependent cellular cytotoxicity; CRBC, chicken red blood cells; LU, lytic units; NK, natural killer cells; SpA, staphylococcal protein A.

J. Clin. Invest.

(c) The American Society for Clinical Investigation, Inc.

$0021-9738 / 89 / 01 / 0278 / 10 \quad \$ 2.00$

Volume 83, January 1989, 278-287
Enhanced susceptibility or resistance of tumor cells to NK mediated lysis cannot be attributed to any structure (or receptor) on the target cell membrane (3). Recent studies would indicate that lack of major histocompatibility (MHC) antigens, especially class I antigens, renders certain tumor cells more susceptible to NK-mediated lysis (4-7). Murine lymphoma cells when selected for loss of $\mathrm{H}-2$ expression were shown to be less malignant when compared to the corresponding wild type control expressing H-2 antigens. Depletion of NK cells from these mice enhanced malignant potential of the $\mathrm{H}-2$ deficient variant and subsequent in vitro assays demonstrated that the H-2 deficient variant and not the wild type was susceptible to NK lysis $(4,5)$. Harel-Bellan and her coinvestigators using a human Epstein Barr virus-transformed B cell line nicely demonstrated in an in vitro system that variants of this cell line, when perturbed in the expression of class I molecules, was particularly sensitive to NK lysis (6). However, in both these studies, there is a possibility, though remote, that susceptibility to NK-mediated lysis is caused by altered expression of other nonclass I molecules as a direct result of mutation in the MHC or as an indirect effect of a reduced class I antigen expression as has been suggested by Storkus et al. (7).

Other investigators using different murine cell lines, transformed by adenoviruses or chemical mutagens, to alter expression of class I antigens, have been unable to confirm the role of class I MHC antigens in protecting against NK-mediated lysis (8-11). In fact, these investigators found that lack of class I antigens was associated with resistance to NK cell killing (8-10).

It is possible that these conflicting observations could have arisen if the different maneuvers used to alter class I antigen expression in the different tumor cell lines variably altered expression of other membrane molecules involved in NK lysis. After all, NK-mediated lysis is a complex process requiring recognition, target cell binding, and lysis of target cells as a result of activating the lytic processes in the effector cells.

In these experiments we used a different approach by utilizing murine monoclonal antibodies to specifically bind and hence "mask" HLA or non-HLA molecules expressed on human tumor targets. We present data to confirm previous observations and show that both class I and II HLA molecules are important in maintaining tumor target cell resistance towards NK cytotoxicity especially with regard to lymphoid-derived tumors. Additionally, our studies indicate that with certain solid tumors, resistance to NK-mediated lysis cannot be entirely explained on the basis of membrane HLA molecules.

\section{Methods}

Cell lines. All cell lines used grow in suspension. Cells were grown in RPMI 1640 containing $10 \%$ fetal calf serum (FCS). The HLA antigen profile of these cell lines and their cell of origin are depicted in Table $I$. 
Table I. HLA Profile and Cell Origin of Cell Lines Used

\begin{tabular}{llcc}
\hline & & \multicolumn{2}{c}{ HLA antigen profile } \\
\cline { 3 - 4 } \multicolumn{1}{c}{ Cell line } & \multicolumn{1}{c}{ Cell of origin } & Class I & Class II \\
\hline K562 & Myeloid & - & - \\
${ }^{*}$ HSB & T lymphoma & + & - \\
${ }^{*}$ JM & T lymphoma & + & - \\
CEM & T lymphoma & + & - \\
Hut 102 & T lymphoma & + & + \\
Hut 79 & T lymphoma & + & + \\
Daudi & B lymphoma & - & + \\
*MST & B lymphoma & + & + \\
*JY & B lymphoma & + & + \\
SB & B lymphoma & + & + \\
U 937 & Monocytic & + & - \\
Y 79 & Retinoblastoma & - & - \\
MDA-MB-134-VI & Breast & - & - \\
NCI-H69 & Lung & + & - \\
Kato-III & Stomach & + & + \\
Du 4475 & Breast & + & - \\
SK-NEP-1 & Kidney-Wilm's & + & - \\
SK-MEL-1 & Melanoma & + & - \\
& & & \\
\hline
\end{tabular}

$(+)$ Denotes presence while $(-)$ denotes absence of HLA antigens on cell membranes as determined by indirect immunofluorescence.

* Cell lines were kindly donated by Dr. V. Engelhardt (University of Virginia Medical Center, Charlottesville, VA). The rest of the cell lines were obtained through the American Type Culture Collections.

In the present studies, cell lines were checked in our laboratory for the presence of membrane class I or II molecules by indirect immunofluorescence using W6/32 (anti-class I) or L243 (anti-class II) murine monoclonals and FITC labeled goat antimouse IgG.

Murine monoclonal antibodies and anti-HLA (Fab) ${ }_{2}$ alloantibodies. Purified supernatants of monoclonals were obtained as follows: L243, L368, 2DI, L01-1, 4H9, Leu 1 (CD5), Leu 4 (CD3), Leu 9 (CD7), and Leu 5b (CD2) from Becton-Dickinson Laboratories, Mountain View, CA; W6/32 from Sera Lab, Westbury, NY; To5 (CD35), R1/69, A8/B5, DK22, To 15, and Leucocyte Common Ag (CD45) from Dako Laboratories, Santa Barbara, CA; BB7.2, BB7.7, BB7.6, L 227, 2.06, and IVA 12 from American Type Culture Collection, Rockville, MD; OKT3 from Ortho Laboratories, Raritan, NJ; Cappell anti-HLA, ABC from Organon TeknikaCappel, West Chester, PA; and H-4 from One Lambda Labs, Los Angeles, CA. BL-11 and BL-2 were kindly donated by Dr. J. Brochier, Hôpital E. Herriot, Lyon, France. ICN anti-DR was obtained from ICN Immunobiologicals, Lisle, IL. BA-1 (CD24) was obtained from Hybritech, San Diego, CA; B1 (Clone H299) was obtained from Coulter Immunol, Hialeah, FL.

W6/32, BB7.7 react with monomorphic determinants on class I HLA molecules, whereas $B B 7.6$ and $B B 7.2$ react with polymorphic determinants on class I molecules (12-14). L243, H4, DK 22, BL-11, BL-2, L227, 2.06, ICN anti-DR, and IVA 12 react with monomorphic determinants on class II HLA molecules, (15-18).

Human alloantibodies that had broad reactivity to both class I and II HLA antigens were obtained from renal dialysis patients who had received multiple blood transfusions. $F(a b)_{2}^{r}$ fragments of these antibodies were prepared by digesting heat inactivated serum with pepsin ( $2 \mathrm{mg}$ enzyme to $1 \mathrm{ml}$ of serum, $\mathrm{pH} 4.5$ ) for $18 \mathrm{~h}$ at $37^{\circ} \mathrm{C}$. The $\mathrm{pH}$ of serum was adjusted to 7.5 after the digestion and the serum supernatant (containing $\mathrm{F}(\mathrm{ab})_{2}$ fragments) was initially dialyzed overnight against $0.005 \mathrm{M}$ phosphate buffer ( $\mathrm{pH} 7.5$ ) and then against PBS (pH 7.2). Contaminating undigested FcIgG could not be removed from these preparations as staphylococcal protein A $(\mathrm{SpA})$ bound very weakly to these alloantibodies. This was determined using FITC-SpA to bind to membrane bound IgG alloantibody. Efficacy of digestion and purity of $\mathrm{F}(\mathrm{ab})_{2}$ fragments was ascertained by $(a)$ Ouchterlony plates, $(b)$ ability of antibody to lyse normal lymphocytes in a complement-dependent microlymphocytotoxicity assay (19) and (c) by indirect immunofluorescence to detect binding of Fc containing antibody to cells using FITC-labeled goat anti-human IgG specific for the heavy chain of the IgG molecule. Data on purity of $F(a b)_{2}^{\prime}$ are illustrated on Fig. 3.

Natural killer assay. Effectors were freshly isolated by Ficoll-Hypaque density gradient centrifugation of blood. NK assay was performed by previously described in vitro techniques. Briefly, $2.5 \times 10^{4}$ ${ }^{51} \mathrm{Cr}$ labeled tumor target cells in RPMI 1640 media and $10 \%$ fetal calf serum were incubated for $4-5 \mathrm{~h}$ with $0.25 \mathrm{ml}$ effector cells (at effector:target ratio 10:1, 25:1, 50:1, and occasionally 100:1) in Falcon plastic tubes (triplicate cultures). Tubes were gently centrifuged $(100 \mathrm{~g}$ for $3 \mathrm{~min}$ ) before the incubation. At the end of the incubation, tubes were centrifuged at $500 \mathrm{~g}$ for $10 \mathrm{~min}$ and percent ${ }^{51} \mathrm{Cr}$ release in the supernatant was evaluated after separately counting both the pellet and supernatant. The sum of pellet and supernatant counts helped determine if targets were uniformly distributed in all the tubes. Percent specific ${ }^{51} \mathrm{Cr}$ release was calculated as: (Experimental \% release) - (spontaneous \% release)/(Maximal \% release) - (spontaneous \% release) $\times 100$. Spontaneous $\%$ release represents target cell release when targets are incubated in media alone. Maximal \% release represents target cell release when targets are incubated with water. Data are also reported in lytic units (LU). A LU is defined as the number of effector cells required to generate $30 \%$ specific ${ }^{51} \mathrm{Cr}$ release from targets and is expressed as $\mathrm{LU} / 10^{6}$ effector cells. The standard deviation of triplicate values in all experiments did not exceed $10 \%$.

Antibody dependent cellular cytotoxicity (ADCC). This assay was performed using techniques identical to that used for the NK assays. Two antibody-target combinations that were previously well studied by other investigators were used as controls $(20,21)$. FeMx melanoma cell line and the rabbit polyclonal antiserum specific for melanoma cancer cells was kindly donated by Dr. John R. Ortaldo from the National Cancer Institute. Maximum ADCC was produced when this antiserum was used at a 1/100 dilution. The second antibody target combination consisted of chicken red blood cells (CRBC) and a rabbit polyclonal antiserum specific for CRBC. (Organon Teknika-Cappell Laboratories). Maximum ADCC was produced when this antiserum was used at a 1/6,000 dilution.

Masking of target cell membrane antigens with monoclonal antibodies. Before the NK assay, ${ }^{51} \mathrm{Cr}$-labeled target cells $(25,000$ in 25 lambda media) were incubated with 25 lambda of appropriately diluted mouse monoclonal to deliver $0.5-1.0 \mu \mathrm{g}$ of antibody. After 30 min incubation with antibody at $4^{\circ} \mathrm{C}$, target cells were washed and then cocultured with or without effector cells (control for spontaneous $\%$ release). Different dilutions of each monoclonal were added to target cells to determine antibody concentration leading to maximum target cell lysis during the NK assay.

Inhibition of $N K$ and $A D C C$ with $S p A$. In these experiments, SpA isolated from $S$. aureus A676 bacteria (Pharmacia Fine Chemicals, Uppsala, Sweden) was used. $2.5 \times 10^{4}{ }^{51} \mathrm{Cr}$ labeled target cells were incubated with appropriate dilutions of antibody at $4^{\circ} \mathrm{C}$ for $30 \mathrm{~min}$, washed, and then reincubated with $50 \mu \mathrm{g}$ of $\mathrm{SpA}$ at $4^{\circ} \mathrm{C}$ for $30 \mathrm{~min}$. Target cells were washed after the SpA incubation before the ADCC and NK assay. Because of variable binding of SpA to the Fc region of the various IgG isotypes and from different animal species, under the culture conditions used, care was taken to confirm binding of SpA to target membrane bound IgG using FITC-labeled SpA. For example, with this technique, $\mathrm{SpA}$ was found to bind very avidly to rabbit anti-chicken RBC but very weakly to rabbit anti-FeMx or to the human anti-HLA alloantibodies that we used. Similarly, SpA bound very avidly to murine monoclonal L243 (IgG 2a anti-DR) and to L227 (IgG 1, anti-DR) but not to several other murine monoclonals with similar IgG isotypes (see Fig. 5). 
Complement-dependent lysis of NK effectors. In additional experiments, effector cells were depleted of NK effectors using complement binding monoclonal antibody specific for cells with NK activity. Since the majority of cells with NK activity are phenotypically CD16 (22), we used Leu $11 \mathrm{~b}$ (CD 16, clone G022, and OKT8 [CD8]). Complement-dependent lysis of NK effectors was performed by previously described techniques (23). Between 5 to $10 \times 10^{6}$ lymphocytes in RPMI containing 5\% FCS were incubated with mouse monoclonal antibody at a concentration of $1 \mu \mathrm{g}$ for $1 \times 10^{6}$ cells. After $30 \mathrm{~min}$ incubation at room temperature, cells were exposed for $1 \mathrm{~h}$ to baby rabbit complement (Pel Freez Lab, Brown Deer, WI, diluted 1:2 in FCS). Control cells were exposed to rabbit complement but no monoclonal antibody. Complement lysis was terminated by washing cells three times with $10 \%$ FCS in RPMI.

Enzyme digestion of effectors. In certain experiments, effectors used in ADCC or NK assays were digested with pronase (Type XIV; Sigma Chemical Co., St. Louis, MO) as previously described (24). Pronase was used at a final concentration of $2 \mathrm{mg} / 10^{7}$ lymphocytes $/ \mathrm{ml}$. After incubation with this enzyme for $30 \mathrm{~min}$ at $37^{\circ} \mathrm{C}$, cells were washed twice with heat-inactivated FCS and resuspended in RPMI containing $10 \%$ FCS. Cell viability determined by trypan blue exclusion was $>85 \%$. Efficacy of digestion was ascertained by indirect immunofluorescence as previously described (24) to determine if rabbit anti-FeMx or normal human IgG bound to Fc receptors on the pronase digested effectors.

Evaluation of target cell membrane antigens after anti-HLA antibody. The effect of anti-HLA-DR on target cell membrane DR antigens was analyzed by incubating $0.5 \times 10^{6} \mathrm{JY}$ and Daudi targets with 1 $\mu \mathrm{g}$ FITC-labeled anti-HLA-DR (L243) for $30 \mathrm{~min}$ at $4^{\circ} \mathrm{C}$. Targets were then washed in culture media and intensity of FITC staining was measured immediately and again after the stained target cells were allowed to incubate in culture media at $37^{\circ} \mathrm{C}$ for 2 and $4 \mathrm{~h}$. Target cells were examined for membrane fluorescence with fluorescence microscopy and also by flow cytometry. With fluorescence microscopy we observed no modulation of HLA-DR antigens (including capping) after FITC anti-HLA-DR.

Target binding assay (conjugate formation). To observe binding of NK cells to their targets (conjugate formation), we used the method of Grimm and Bonavida (25). $1 \times 10^{6}$ nonadherent (plastic petri dish) PBMC were mixed with $0.5 \times 10^{6}$ targets in a total volume of $1 \mathrm{ml}$ culture medium (RPMI with $15 \%$ FCS). The cell mixture was gently centrifuged at $250 \mathrm{~g}$ for $5 \mathrm{~min}$ and then incubated for $30 \mathrm{~min}$ at $37^{\circ} \mathrm{C}$ in a $5 \% \mathrm{CO}_{2}$ humidified atmosphere. Cells were gently resuspended and 200 effector cells were counted. The percent binding of effectors to targets was calculated as follows: number of single effectors bound to single targets divided by the total number of effectors by $100 \%$.

Single cell assay for $N K$ lysis. Effector cell lysis of bound target cells was evaluated in the single cell assay for killing according to the method of Grimm and Bonavida (25). $1 \times 10^{6}$ nonadherent PBMC (in $0.5 \mathrm{ml}$ ) were mixed with $1 \times 10^{6}$ targets (in $0.5 \mathrm{ml}$ ). The cell suspension was gently centrifuged ( $250 \mathrm{~g}$ for $5 \mathrm{~min}$ ) and then allowed to incubate in $5 \% \mathrm{CO}_{2}$ for $30 \mathrm{~min}$ at $37^{\circ} \mathrm{C}$. After the incubation, cells were gently resuspended and then added to $1 \mathrm{ml}$ of a $0.5 \%$ agarose solution maintained in liquified state at $42^{\circ} \mathrm{C}$. The cell agarose solution was pipetted on a $60-\mathrm{mm}$ tissue culture plate and allowed to solidify at room temperature. The agarose was then overlaid with RPMI and incubated at $37^{\circ} \mathrm{C}$. After $2 \mathrm{~h}$, medium was aspirated and $2 \mathrm{ml}$ of $0.2 \%$ trypan blue added. The plates were then examined under an inverted microscope with phase contrast. The percentage of dead target cells in conjugates was calculated by counting 100 conjugates and evaluating number of conjugates with dead targets.

Lysis of tumor targets with large granular lymphocytes (LGL) granules. Granules from rat LGL were kindly provided by Dr. Pierre Henkart (Immunology Branch, NCI, Bethesda, MD). We followed previously described technique (26). LGL granules (RNK 7P7A, 7,500 $\mathrm{U} / \mathrm{ml}$ ) was diluted in PBS without calcium. 200 lambda of granules with the desired cytolysin activity was added to 200 lambda ${ }^{51} \mathrm{Cr}$ labeled tumor targets $\left(2 \times 10^{4}\right)$ in RPMI with $0.2 \%$ BSA. After $1 \mathrm{~h}$ incubation at room temperature, cytotoxicity was evaluated by determining specific ${ }^{51} \mathrm{Cr}$ release as described in the NK assay. To control for nonspecific lysis, LGL granules were diluted in PBS containing calcium, which completely abrogated the cytolysin effect.

\section{Results}

Effect of masking HLA determinants on tumor targets in the NK assay. NK assays were performed utilizing as targets 11 cultured allogeneic lymphoblastoid cell lines and seven solid tumor cell lines that grew in suspension (Table I, Table II, and Fig. 1). In some experiments, ${ }^{51} \mathrm{Cr}$ labeled target cells were
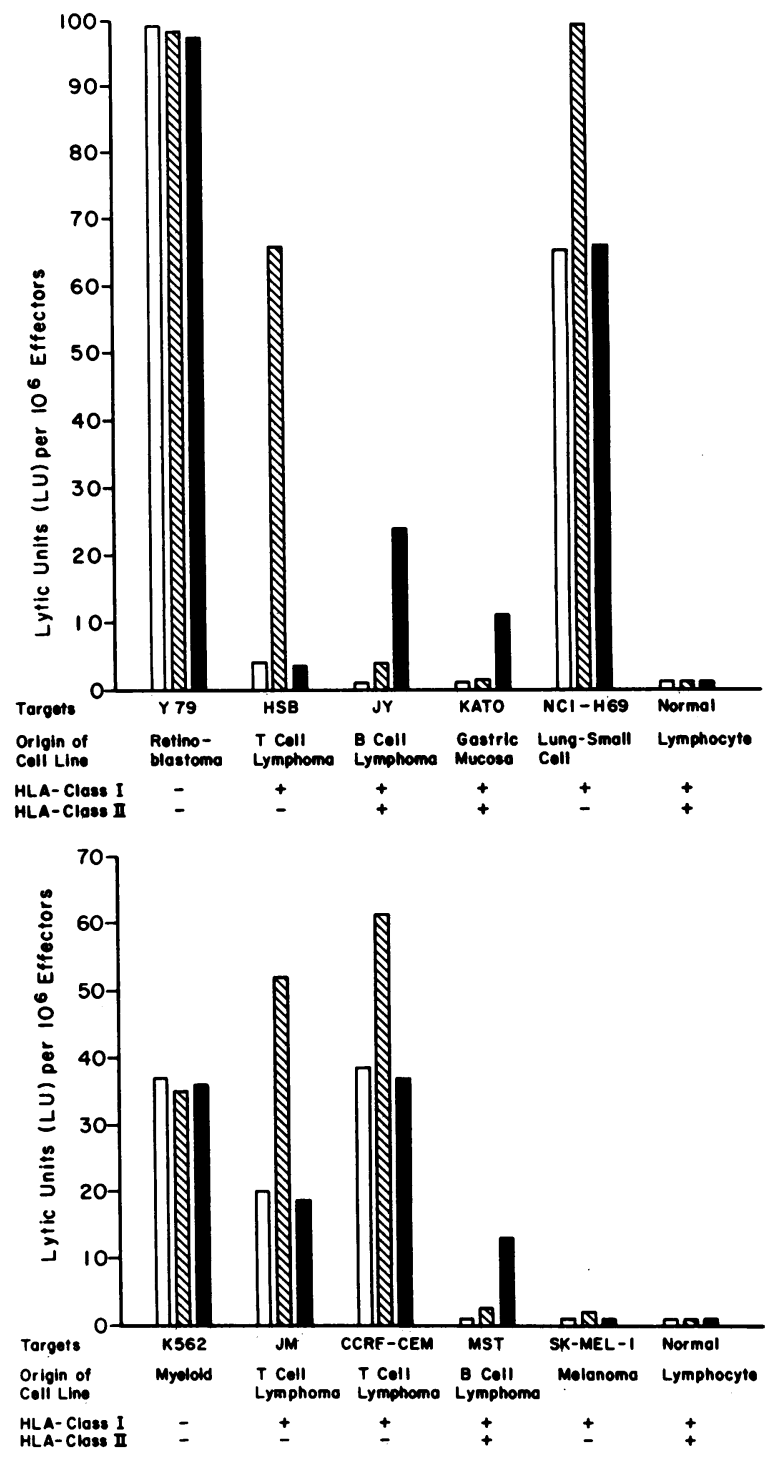

Figure 1. Cultured tumor target cell lines known to be resistant and sensitive to NK lysis were subjected to NK lysis with fresh peripheral blood mononuclear cells (NK effectors) obtained from normal volunteers. Two different effectors were used, one for each panel. Before the NK assay ${ }^{51} \mathrm{Cr}$ labeled target cells were either not incubated with antibody (denoted as $\square$ ) or incubated with anti-HLA-AB monoclonal (W 6/32, denoted as $₫$ ), or incubated with anti-HLA-DR (L243, denoted as $\square$ ). Antibody was washed off target cells before incubation with effectors. + and - on abscissa denote presence or absence of HLA class I or II antigens on the cell membrane of tumor targets as determined by indirect immunofluorescence in our laboratory. 
Table II. Natural Killer Assay: Effect of Masking HLA Determinants on Targets with Murine Monoclonal Antibodies

\begin{tabular}{|c|c|c|c|c|c|c|c|c|}
\hline \multirow[b]{4}{*}{ Effector:Target ratio } & \multicolumn{8}{|c|}{ \% Specific ${ }^{51} \mathrm{Cr}$ lysis } \\
\hline & \multicolumn{4}{|c|}{ Effector 1} & \multicolumn{4}{|c|}{ Effector 2} \\
\hline & \multicolumn{2}{|c|}{ JY target } & \multicolumn{2}{|c|}{ HSB target } & \multicolumn{2}{|c|}{ Daudi target } & \multicolumn{2}{|c|}{ JM target } \\
\hline & $\begin{array}{c}\text { No } \\
\text { antibody }\end{array}$ & $\begin{array}{c}\text { Anti- } \\
\text { HLA-DR }\end{array}$ & $\begin{array}{c}\text { No } \\
\text { antibody }\end{array}$ & $\begin{array}{c}\text { Anti- } \\
\text { HLA-AB }\end{array}$ & $\begin{array}{c}\text { No } \\
\text { antibody }\end{array}$ & $\begin{array}{c}\text { Anti- } \\
\text { HLA-DR }\end{array}$ & $\begin{array}{c}\text { No } \\
\text { antibody }\end{array}$ & $\begin{array}{c}\text { Anti- } \\
\text { HLA-AB }\end{array}$ \\
\hline $100: 1$ & 0 & 38.3 & 16.4 & 81.4 & 4.5 & 51.9 & 47.0 & 68.3 \\
\hline $50: 1$ & 0 & 31.0 & 4.3 & 64.8 & 1.2 & 46.5 & 24.4 & 50.3 \\
\hline $25: 1$ & 0 & 15.7 & 0.1 & 48.3 & 1.3 & 30.3 & 14.0 & 36.2 \\
\hline $10: 1$ & 0 & 13.4 & 0 & 18.9 & 0 & 13.8 & 5.4 & 17.1 \\
\hline
\end{tabular}

$2.5 \times 10^{4}{ }^{51} \mathrm{Cr}$ labeled cell lines were incubated for $30 \mathrm{~min}$ at $4^{\circ} \mathrm{C}$ with the mouse monoclonal antibodies reactive to HLA determinants, washed twice and then subjected to NK lysis over $4 \mathrm{~h}$. JY and Daudi are B lymphoblastoid cell lines while HSB and JM are T lymphoblastoid cell lines lacking HLA-DR determinants. Anti-HLA-DR is the L243 monoclonal while anti-HLA, AB is the W6/32 monoclonal.

initially interacted with mouse monoclonal antibodies specific for either class I or II HLA antigens, so as to "block" or mask these cell membrane determinants. Target cells were washed to remove unbound antibody before coculturing them with effectors in the NK assays. Washing of target cells after antibody pretreatment was essential as this procedure $(a)$ decreased or prevented antibody interaction with effector cells and $(b)$ removed preservatives or proteases that can be present in monoclonal antibody supernatants, thus reducing nonspecific effects on effectors and targets.

From Fig. 1 and Table II, it is evident that when HLA antigens were present on tumor target cells, binding of antiHLA antibody to the target cells led to enhanced NK lysis. This was particularly true for lymphoblastoid cell lines and to a lesser extent with solid tumor cell lines. SK-MEL-1 was particularly resistant to NK lysis despite use of several monoclonals directed at class I determinants. Similar enhancement in lysis was observed with freshly obtained allogenic leukemic cells (data not shown). Secondly, there was heightened lysis of cell lines lacking HLA antigens (e.g., K562, Y79). Pretreatment with anti-HLA monoclonals did not increase the already enhanced lysis.

For optimal "masking" of HLA antigen determinants, murine monoclonals had to be used at concentrations of 0.5 to 1.0 $\mu \mathrm{g}$ per 25,000 targets although some enhancement of the NK lysis was observed with less quantities of monoclonal antibody (Fig. 4). Of particular importance, to observe some enhancement of NK lysis, one required more antibody than that required to detect antibody binding by indirect immunofluorescence, i.e., by at least two more dilutions (a factor of four).

Effect of masking non-HLA determinants on tumor targets in the NK assay. It became important to determine if the observed enhancement of NK lysis was unique to masking of HLA determinants on tumor targets. 15 monoclonals reactive to non-HLA determinants on lymphoid tumor cells were treated in a similar fashion. Seven of these monoclonals are exemplified in Table III. The other eight monoclonals tested reacted to the following non-HLA membrane determinants: $B$ lymphocyte determinants, B1 (CD20, IgG 2a); BA 1 (CD24, IgM); To 15 (CD22, IgG 2b); immunoglobulin determinants, anti-lambda (IgG 1); T lymphocyte determinants, Leu 9 (CD7, IgG 2a); Leu 5b (CD2, IgG 2a); Leu 1 (CD5, IgG 2a); and leukocyte determinants, leukocyte Common Antigen (CD45,
IgG 1). As exemplified on Table III, no enhancement of NK lysis was observed after using monoclonals reactive to these non-HLA determinants.

Effect of masking HLA determinants on normal cell targets in the NK assay. We observed no NK lysis of normal autologous and allogenic lymphocytes (Fig. 1), and enriched B lymphocytes and platelets (data not shown), despite the presence of these anti-HLA monoclonals. Similarly, normal allogeneic lymphocytes subjected to blast transformation with pokeweed mitogen or concanavalin-A were resistant to NK lysis despite presence of anti-HLA monoclonals. No conjugate formation was observed between these blasts and NK effectors. This latter observation would indicate that normal well differentiated lymphocytes, despite being allogeneic, are not lysed by NK cells even after blast transformation and masking of HLA antigens with monoclonal antibodies.

Importance of class I or II HLA molecules and their epitopes in preventing $N K$ lysis. As exemplified in Fig. 1, when tumor targets expressed both class I and class II HLA determinants (e.g., MST, JY, Kato III and [not shown] Hut 102 and 5B), then antibodies to class I antigens had no enhancing effect despite using fivefold amount of antibody and even though by immunofluorescence there was strong binding of class I antibodies to these targets. Enhancing effect was seen only with anti-class II antibodies. Addition of both class I and II antibodies did not lead to increased enhancement. One exception, however, was the HUT 78 Sezary T cell line (interleukin 2 secretor) where anti-class I antibody led to enhanced NK lysis despite the presence of class II antigens on the cell line (Table III). This could not be explained on the basis of IL-2 or other factors in the supernatants as Hut 78 supernatants or recombinant IL-2 did not enhance NK lysis of JY targets when exposed to anti-class I antibody.

From Table III it became evident that not all anti-HLA monoclonals were capable of enhancing tumor target cell lysis. In particular, enhanced lysis was observed with monoclonals reactive to nonpolymorphic or monomorphic determinants on the HLA molecule, e.g., L243, H4, W6/32, BB7.7, Cappell anti-HLA or to the beta-2 microglobulin molecule. We could not, however, demonstrate enhancement of NK lysis using some other monoclonals with similar isotypes and that were also reactive to monomorphic determinants on the HLA molecule (data not shown), i.e., L227 (anti-DR, IgG 1), IVA 12 
Table III. Binding of Mouse Monoclonal Antibodies to Tumor Target Cell Antigenic Determinants:

\begin{tabular}{|c|c|c|c|c|c|c|c|}
\hline \multirow[b]{3}{*}{ Mouse monoclonal antibody } & \multirow[b]{3}{*}{$\begin{array}{l}\text { Hybridoma } \\
\text { clone }\end{array}$} & \multirow[b]{3}{*}{$\begin{array}{c}\text { IgG } \\
\text { subclass }\end{array}$} & \multicolumn{5}{|c|}{ LU $/ 10^{6}$ effectors } \\
\hline & & & \multicolumn{3}{|c|}{ Effector 3} & \multicolumn{2}{|c|}{ Effector 4} \\
\hline & & & $\begin{array}{c}\text { HSB } \\
\text { target }\end{array}$ & $\begin{array}{c}\text { JY } \\
\text { target }\end{array}$ & $\begin{array}{c}\text { Hut } 78 \\
\text { target }\end{array}$ & $\begin{array}{c}\text { JY } \\
\text { target }\end{array}$ & $\begin{array}{l}\text { Daudi } \\
\text { target }\end{array}$ \\
\hline None & - & - & 0.9 & $<1$ & 28.6 & 21.2 & 38.0 \\
\hline Anti-HLA-DR & L243 & IgG 2a & - & $* 19.2$ & $* 68.0$ & $* 67.0$ & ${ }^{*} 111.4$ \\
\hline Anti-HLA-DR & $\mathrm{H} 4$ & IgG 2b & - & $* 23.4$ & $* 66.2$ & $* 54.3$ & $* 89.1$ \\
\hline Anti-HLA-DR & BL-22 & IgG 2b & - & $<1$ & 23.4 & 29.2 & 40.3 \\
\hline Anti-HLA-AB & W6/32 & IgG 2a & $* 71.4$ & 2.0 & $* 52.6$ & 27.0 & - \\
\hline Anti-HLA-AB \& $\beta 2$ micro & BB7.7 & IgG 2b & $* 69.4$ & 1.4 & $* 55.8$ & 21.3 & - \\
\hline Anti-HLA-BW6 & BB7.6 & IgG 1 & 0.7 & $<1$ & 16.2 & 22.3 & - \\
\hline Anti-HLA-AB & Cappell & IgG 1 & $* 59.8$ & $<1$ & $* 53.1$ & 18.3 & - \\
\hline Anti- $\beta$ microglobulin & L368 & IgG 1 & $* 66.1$ & 1.7 & $* 53.4$ & 23.5 & - \\
\hline Anti- $C_{3} b(C R$ 1) & To 5 & IgG 1 & - & $<1$ & - & 18.1 & 36.3 \\
\hline Anti-IgM & $\mathrm{R} 1 / 69$ & IgG 1 & - & $<1$ & - & 22.3 & 39.9 \\
\hline Anti-kappa & A8/B5 & IgG 1 & - & $<1$ & - & 20.4 & 34.4 \\
\hline Anti-leukocyte (HLe 1) & 2D1 & IgG 1 & $<1$ & $<1$ & 23.8 & 19.4 & 38.4 \\
\hline Anti-transferrin & L01.1 & IgG 2a & $<1$ & $<1$ & 24.6 & - & - \\
\hline Anti-T cell, NK (CD7) & $4 \mathrm{H} 9$ & IgG 2a & $<1$ & - & - & - & - \\
\hline Anti-OKT3 (CD3) & OKT3 & IgG 2a & $<1$ & - & 25.6 & - & - \\
\hline
\end{tabular}

${ }^{51} \mathrm{Cr}$ labeled cell lines were exposed to various mouse monoclonal supernatants reactive to HLA and non-HLA membrane determinants, washed and then subjected to NK lysis. The origin of cell line and class of HLA antigens on their cell surface are as follows: HSB, T cell with HLA class I; JY, B cell with HLA Class I and II; Hut 78, T cell (Sezary) with HLA class I and II; Daudi: B cell with HLA class II. In this table, points with no data indicate that NK assays were not performed as the cell lines showed no monoclonal antibody binding when checked by indirect immunofluorescence. This table contains representative data from two of the seven different effectors tested. ${ }^{*}$ Represents highly significant enhancement of NK activity. There were $<10 \%$ SD in all experiments.

(anti-DR and DP, IgG 1) ICN (anti-DR, IgG 2a), 2.06 (anti$\mathrm{DR}, \mathrm{Ig} \mathrm{G1})$ as well as to some monoclonals reactive to polymorphic determinants of the HLA molecule, i.e., BB7.6 (antiHLA-BW6, IgG1), BB7.2 (anti-HLA-A2, IgG 2b). By indirect immunofluorescence all these nonenhancing antibodies were strongly reactive to the targets tested. The ability of only certain anti-HLA monoclonals to enhance NK lysis suggests that certain epitopes present on the HLA monomorphic determinants and the beta-2-microglobulin are important in rendering target cells resistant to NK lysis.

Effect of masking HLA determinants on effectors in the NK assay. It is possible that enhanced NK lysis may result from monoclonal antibody effect on HLA antigens present on effectors. We did not feel that this was the case as targets pretreated with antibody were washed before co-culturing with effectors. Further, using K562 and Y79 targets, which lack both class I and II HLA molecules, no enhancing effect was observed even when NK assays were performed with effectors pretreated with anti-HLA sera and then washed or with antiHLA sera being present throughout the NK assay.

Studies to evaluate effectors responsible for enhanced NK lysis. It became important to determine whether the enhanced lysis observed in the presence of anti-HLA antibody was indeed mediated via NK effectors. Since the majority of NK cells have CD16 phenotype (with some cells coexpressing CD8) (22), experiments were repeated with effectors depleted of cells with such phenotypes using a complement-dependent lysis system. Data in Table IV, which are representative of five different experiments, indicate that the enhancing effect of
anti-HLA, DR antibody was maximally abrogated when effectors were depleted of cells with CD16 phenotype. Depletion of the CD8 subpopulation did not affect NK killing. These data thus support the concept that the enhanced lysis was mediated via effectors having similar phenotypes as effectors with NK activity. Depletion of T cells with anti- Leu-1 mouse monoclonal (CD5, Becton-Dickinson), did not decrease the enhanced tumor cell lysis (data not shown).

Mechanism of enhanced NK lysis. After we determined that the enhanced NK activity with targets exposed to monoclonal anti-HLA antibody was not due to an effect on effectors, it became important to clarify how this antibody made targets more susceptible to NK lysis. Experiments were aimed at studying the effect of anti-HLA antibodies on $(a)$ modulating target membrane HLA antigens, $(b)$ binding affinity of effectors to target cells, i.e., conjugate formation and (c) effect on postbinding target cell lysis. Data from Table $\mathrm{V}$ indicate that antibody binding to target cells did not lead to shedding or internalization of membrane HLA antigens especially since we observed no quantitative decrease in the FITC staining of membrane HLA antigens during the culture period. Additionally, modulation of membrane HLA antigens appeared unlikely as we observed no capping over the 4-h period. Secondly, anti-HLA antibody did not appear to enhance conjugate formation and furthermore, we observed no increase in the number of effectors binding to a single target cell. From Table V, data would indicate that anti-HLA antibody rendered target cells more susceptible to postbinding lysis. To further elucidate the mechanism of enhanced postbinding NK 
Table IV. Enhancing Effect of Anti-HLA-DR Antibodies on NK Activity Abrogated when Effectors Depleted of Cells with CD16 and CD8 Phenotypes

\begin{tabular}{|c|c|c|c|c|c|c|c|}
\hline & \multicolumn{7}{|c|}{ \% Specific ${ }^{51} \mathrm{Cr}$ lysis } \\
\hline & \multicolumn{3}{|c|}{ Effector 5} & \multicolumn{4}{|c|}{ Effector 2} \\
\hline & \multicolumn{3}{|c|}{ Phenotypes depleted from effectors } & \multicolumn{4}{|c|}{ Phenotypes depleted from effectors } \\
\hline & None & CD16 & $\mathrm{CD} 16+\mathrm{CD} 8$ & None & $\mathrm{CD} 16$ & CD8 & $\mathrm{CD} 16+\mathrm{CD} 8$ \\
\hline Target K562 & 77.8 & 3.8 & 4.2 & 53.9 & 4.3 & 51.2 & 4.5 \\
\hline Target JY lymphoblast & 1.3 & 2.1 & 0 & 9.3 & 6.1 & 7.2 & 3.8 \\
\hline Target JY + anti-HLA-DR (L243) & 24.0 & 6.1 & 1.9 & 68.3 & 12.8 & 54.2 & 12.9 \\
\hline Target Daudi & 3.0 & 7.6 & 1.1 & 13.8 & 1.0 & 11.2 & 0.8 \\
\hline Target Daudi + anti-HLA-DR (L243) & 53.8 & 8.1 & 4.8 & 77.8 & 11.1 & 60.1 & 7.2 \\
\hline
\end{tabular}

Effectors were depleted of cells with CD8 and CD16 phenotypes using complement binding monoclonal antibodies (Leu 11b and OKT8). Control effectors were exposed to rabbit complement and a monoclonal antibody nonreactive to effector cells. In these experiments, effector/target ratio was 25:1. Similar data were obtained with ratios of 50:1.

lysis after pretreating targets with anti-HLA antibodies, studies were conducted with purified LGL granules. Data in Table VI indicate that the anti-HLA monoclonals did not increase the susceptibility of the tumor targets to the LGL granules. It is, therefore, possible that the enhanced postbinding lysis (after pretreating targets with anti-HLA antibodies) results from enhanced triggering of NK effector cells when HLA antigens on tumor targets are masked by the antibody.

Experiments to exclude the possibility of $A D C C$. It is possible that the enhanced NK lysis of tumor targets observed in the presence of anti-HLA monoclonals are a result of ADCC and not NK lysis. ADCC did not, however, appear to be a satisfying explanation for our observations as it became difficult to explain why all anti-HLA murine monoclonals with similar isotypes did not lead to enhanced target cell lysis, despite demonstrating avid binding to HLA determinants. Additionally, under the conditions of the assay, none of the murine monoclonals binding to non-HLA determinants led to enhanced NK lysis (Table III).

Three different experimental approaches were, however, performed to exclude the possibility of ADCC. Firstly, experiments were performed using effectors pretreated with pronase to digest FcIgG receptors, which are important in ADCC. In these experiments, as a control, we used a well-studied, ADCC-mediated lysis of tumor target using a rabbit antibody that binds to non-HLA antigen present on human melanoma cells (Table VII) (21). ADCC-mediated lysis of FeMx targets with the rabbit antibody was markedly reduced using pronase digested effectors, thus demonstrating that the FcIgG receptors were effectively digested. Despite FcIgG receptor digestion, enhanced lysis of tumor targets was not reduced in the NK system with antibodies (both monoclonal and alloantibodies) that bound to HLA determinants on tumor targets. This lack of inhibition cannot be explained on the basis of increased affinity of murine IgG to partially digested human FcIgG receptors as data in Fig. 2 would argue against this possibility. Binding affinity of the various animal IgG to human FcIgG was compared by elucidating the binding of lymphocytes to serum IgG as previously described (27). As can be seen from Fig. 2, rabbit, but not murine IgG bound very avidly to human FcIgG receptors present on lymphocytes. Hence, ADCC resulting from partially digested or undigested FcIgG receptors should have been evident with the rabbit antibody, which has a higher affinity for the receptors.

Table V. Effects of Anti-HLA Antibodies on Events Leading to Target Cell Lysis

\begin{tabular}{|c|c|c|c|c|c|c|c|}
\hline & \multicolumn{3}{|c|}{$\begin{array}{l}\text { Density of class II antigens on target membrane } \\
\text { after addition of FITC labeled anti-HLA-DR }\end{array}$} & \multicolumn{2}{|c|}{$\begin{array}{l}\text { Percentage of effectors binding to } \\
\text { target (i.e., conjugate formation) }\end{array}$} & \multicolumn{2}{|c|}{$\begin{array}{l}\text { Percentage of targets lysed } \\
\text { within target conjugate }\end{array}$} \\
\hline & \multicolumn{3}{|c|}{ Mean peak channel \pm SD } & \multirow{2}{*}{$\begin{array}{c}\text { Before } \\
\text { anti-HLA-DR }\end{array}$} & \multirow{2}{*}{$\begin{array}{l}\text { After } \\
\text { anti-HLA-DR }\end{array}$} & \multirow{2}{*}{$\begin{array}{c}\text { Before } \\
\text { anti-HLA-DR }\end{array}$} & \multirow{2}{*}{$\begin{array}{c}\text { After } \\
\text { anti-HLA-DR }\end{array}$} \\
\hline & $\mathbf{O h}$ & $2 \mathrm{~h}$ & $4 \mathrm{~h}$ & & & & \\
\hline & $173 \pm 13$ & $166 \pm 16$ & $171 \pm 18$ & & & & \\
\hline Effector 6 & & & & 22.2 & 20.3 & 10.2 & 85.6 \\
\hline Effector 2 & & & & 19.4 & 21.2 & 6.4 & 91.2 \\
\hline Effector 7 & & & & 15.8 & 16.5 & 14.6 & 79.8 \\
\hline
\end{tabular}

Data in this table were obtained using JY lymphoblastoid target cells and anti-HLA-DR (L243). The effect of anti-HLA-DR on target cell membrane DR antigens was analyzed by incubating JY targets with FITC labeled anti-HLA-DR (L243). JY targets were washed and then allowed to incubate at $37^{\circ} \mathrm{C}$ for varying periods. Target cells were examined by flow cytometry and fluorescence microscopy to check for modulation of HLA determinants. No capping was observed. In some experiments, targets were exposed to anti-HLA-DR and then cocultured with NK effectors (as described in Methods) to visually determine effector binding to targets (conjugate formation) and evaluate lysis of target cell within the conjugate. 
Table VI. Effect of Anti-HLA Monoclonals on LGL Granule-mediated Lysis of Tumor Targets

\begin{tabular}{|c|c|c|c|c|c|c|}
\hline \multirow{2}{*}{$\frac{\text { LGL granules }}{\text { LU/2 } \times 10^{4} \text { targets }}$} & \multicolumn{6}{|c|}{$\%$ Specific ${ }^{51} \mathrm{Cr}$ release } \\
\hline & Daudi & Daudi + L243 & JY & $J Y+L 243$ & HSB & HSB + W6/32 \\
\hline 150 & 92.9 & 92.8 & - & - & - & - \\
\hline 75 & 89.8 & 76.7 & - & - & - & - \\
\hline 37.5 & 90.8 & 52.4 & 48.1 & 32.1 & 44.4 & 38.4 \\
\hline 18.75 & 72.1 & 34.7 & 37.7 & 25.8 & 38.1 & 33.5 \\
\hline 9.4 & 26.9 & 13.5 & 23.1 & 15.8 & 27.6 & 23.1 \\
\hline 4.7 & 14.4 & 7.9 & 19.8 & 7.1 & 22.2 & 10.2 \\
\hline
\end{tabular}

${ }^{51} \mathrm{Cr}$ labeled cell lines were incubated with the various anti-HLA mouse monoclonals (L243 anti-DR, W6/32 anti-HLA-AB), washed and then exposed to LGL granules. $2 \times 10^{4}$ targets in $0.2 \mathrm{ml} \mathrm{RPMI} \mathrm{(with} \mathrm{Hepes} \mathrm{buffer)} \mathrm{were} \mathrm{interacted} \mathrm{with} 0.2 \mathrm{ml}$ LGL granules having varying cytolysin activity. 1 LU of LGL granule is defined as the amount of cytolysin that will cause $50 \%$ lysis of a $1-\mathrm{ml}$ suspension containing $0.2 \%$ SRBC.

In the second series of experiments (Fab)' ${ }_{2}^{\prime}$ fragments of antibody were used to mask HLA determinants on tumor targets as the Fc portion of IgG is essential to mediate ADCC. It was not possible in our laboratory to obtain (Fab) ${ }_{2}^{\prime}$ fragments of murine monoclonals W6/32, L243, and L368 without affecting their binding avidity to cell membrane determinants and without significant Fc contamination despite using pepsin digestion techniques described by Parham (28). Our experience has been shared by other investigators who have demonstrated rapid degradation of the (Fab)' monoclonal proteins $(29,30)$. Hence, (Fab)' fragments of human anti-HLA antibodies were used. Fig. 3 exemplifies data from two of the five alloantibodies. As illustrated in the bottom two panels, there was significant enhancement in NK lysis with (Fab)' anti-HLA alloantibodies even when used in dilutions containing no intact FcIgG anti-HLA alloantibody. One cannot attribute the enhanced NK lysis to ADCC mediated by contaminating intact FcIgG anti-HLA antibodies that cannot be detected by indirect immunofluorescence mainly because to observe any enhanced NK lysis in our experimental system significant amounts of FcIgG antibody had to be present. As depicted in the top panel of Fig. 3, enhanced NK lysis was not observed even when by indirect immunofluorescence there was enough FcIgG binding to $60 \%$ of cells.

Because of the inability to prepare (Fab) ${ }_{2}^{\prime}$ fragments with the mouse monoclonals, another technique was utilized to prevent the Fc portion of the antibody from binding to Fc receptors present on effectors. This was accomplished with $\mathrm{SpA}$, which several investigators have used to effectively inhibit ADCC (31-33). In control experiments, another wellstudied ADCC mediated lysis of targets was used, i.e., lysis of CRBC with rabbit anti-CRBC antibody. The rabbit anti-FeMx system could not be used because of weak binding of FITC SpA to this antibody. Experiments using SpA to inhibit ADCC demonstrated that $\mathrm{SpA}$ inhibited ADCC mediated by rabbit anti-CRBC but did not inhibit enhanced NK lysis mediated by the anti-HLA monoclonals (Fig. 4) despite avid binding of SpA to the anti-HLA monoclonals (Fig. 5).

\section{Discussion}

Data from the present investigations indicate that MHC gene products are important in maintaining resistance of tumor targets to NK lysis as has been proposed by others (4-7). Unlike other investigators, we utilized a somewhat direct approach by employing monoclonal antibodies to HLA determinants to alter or mask the amount of MHC determinants on the tumor target cells. Our studies indicate that class II HLA determinants also impart resistance to tumor targets against NK-mediated lysis. Previous studies have mainly focused on the protective role of class I antigens as their techniques did not allow for studying class II antigens (4-7). When tumor targets express both class I and II molecules, then NK lysis is

Table VII. Enzyme Digestion of FcIgG Receptors on Effectors: Effect on NK and ADCC

\begin{tabular}{|c|c|c|c|c|c|c|}
\hline & \multicolumn{2}{|c|}{ Effector 1} & \multicolumn{2}{|c|}{ Effector 2} & \multicolumn{2}{|c|}{ Effector 3} \\
\hline & $\begin{array}{l}\text { Control } \\
\text { effectors }\end{array}$ & $\begin{array}{l}\text { Pronase } \\
\text { digested }\end{array}$ & $\begin{array}{l}\text { Control } \\
\text { effectors }\end{array}$ & $\begin{array}{l}\text { Pronase } \\
\text { digested }\end{array}$ & $\begin{array}{l}\text { Control } \\
\text { effectors }\end{array}$ & $\begin{array}{l}\text { Pronase } \\
\text { digested }\end{array}$ \\
\hline \multicolumn{7}{|l|}{ ADCC lysis } \\
\hline FeMx & 5.3 & 1.2 & 5.3 & 0.4 & 19.8 & 2.0 \\
\hline FeMx + rabbit anti-FeMx & 25.1 & 7.4 & 26.1 & 4.8 & 75.0 & 19.4 \\
\hline \multicolumn{7}{|l|}{ NK lysis } \\
\hline JY & 5.7 & 1.6 & 9.3 & 0.8 & 1.3 & 0 \\
\hline JY + anti-HLA, DR (L243) & 22.3 & 19.0 & 29.8 & 23.1 & 24.0 & 21.6 \\
\hline $\mathrm{JY}+$ anti-HLA alloantibody $3 \mathrm{SH}$ & 50.2 & 56.3 & 56.1 & 47.5 & 39.4 & 36.5 \\
\hline
\end{tabular}

In the ADCC assay, FeMx melanoma cells were used as targets and the rabbit antibody was used at a dilution of 1:100. The effector to target ratio was 100:1. In the NK assay the effector to target ratio was 25:1. Similar data were obtained at ratios of 50:1. Effectors were digested with pronase $(2 \mathrm{mg} / \mathrm{ml})$ for $30 \mathrm{~min}$ at $37^{\circ} \mathrm{C}$. Efficacy of FcIgG receptor digestion was evaluated by the binding of rabbit and human serum IgG (24). By indirect immunofluorescence no serum IgG binding could be detected on pronase-digested cells. 


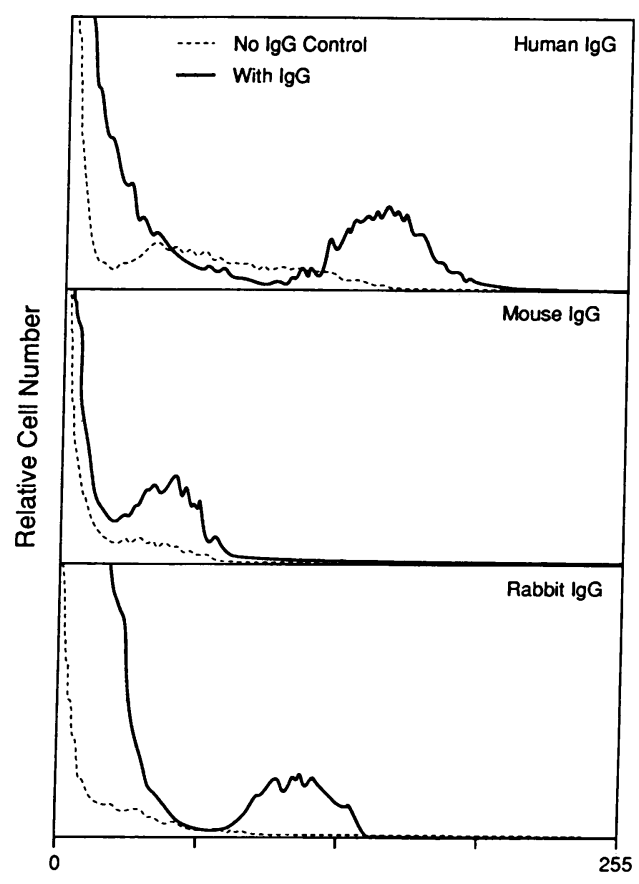

Log Fluorescence Intensity of IgG Binding.

Figure 2. Comparison of binding avidity of human, mouse and rabbit serum IgG to human FcIgG receptors on lymphocytes. Peripheral blood human lymphocytes depleted of macrophages (by plating) were incubated at $37^{\circ} \mathrm{C}$ for $2 \mathrm{~h}$ in media with $5 \%$ FCS to elute off IgG already bound to FcIgG receptors as previously demonstrated (27). Cells were then washed $\times 2$ with warm media prior to incubating with $1 / 20$ dilutions of various sera $\left(4^{\circ} \mathrm{C}\right.$ for $\left.30 \mathrm{~min}\right)$. Cells were washed at $4^{\circ} \mathrm{C}$ before staining with FITC labeled (Fab)' human, mouse or rabbit IgG. Cells were examined by flow cytometry. Background control fluorescence (dashed lines) was determined by incubating cells (after the $2 \mathrm{~h}$ elution step) with FITC antibody. Sera used had no antilymphocytic activity as determined by a complement dependent microlymphocytotoxicity technique (19).

enhanced predominantly when the class II molecules are masked although there are exceptions as we observed with the Hut 78 cell line when, despite the presence of class II molecules, NK lysis occurred after masking of class I molecules. The enhanced lysis of tumor targets after interaction with anti-HLA antibodies was not due to increased binding affinity of effectors to target cells (i.e., conjugate formation), but an effect of increased postbinding target cell lysis. Experiments with LGL granules indicate that the enhanced postbinding lysis (after masking HLA antigens) was not due to increased susceptibility of tumor targets to cytolysin. These data suggest that HLA antigens on tumor targets inhibit the triggering of effector cells (and release of cytolysins) after recognition and binding of NK cells to target cells.

Other investigators who used a similar approach as we did failed to support our observations $(7,34)$. Technical differences may explain in part, these differing observations. During earlier studies we realized the necessity of washing the target cells after preincubation with the monoclonal antibody and before coculturing with effector cells. Such an approach led to consistency in our data as perhaps there was minimal interaction of antibody with effector cells and more importantly the wash step removed preservatives or proteases (released from dying hybridoma cells) that can be present in monoclonal an- tibody supernatants. Secondly, previous investigators employed monoclonals reactive to class I determinants. It is, therefore, possible that lack of enhancement may result if tumor targets also expressed class II molecules. Thirdly, our studies would indicate that the quantity of monoclonals used was critical in bringing out an enhancing NK effect. For optimal enhancing effect, 25,000 targets required to be preincubated with $0.5-1.0 \mu \mathrm{g}$ of monoclonal antibody.

The enhanced NK lysis in the presence of anti-HLA antibodies was due to effectors with the NK phenotype (i.e., CD16) and, in addition, not a result of ADCC. Removal of cells with the CD16 phenotypes from the effector cell population maximally abrogated the enhanced NK lysis, while no reduction in NK enhancement was observed after depletion of $T$ cells with the CD5 phenotype from the effector population. Since effectors with the NK phenotype can also mediate ADCC, experiments were performed to exclude this possibility. Firstly, digestion of FcIgG receptors from effectors with pronase significantly reduced ADCC-mediated lysis of FeMx targets by rabbit anti-FeMx. However, use of pronase digested effectors did not reduce the enhanced NK lysis of targets observed with anti-HLA antibody (with both monoclonals and alloantibody). Secondly, enhanced NK lysis was observed de-

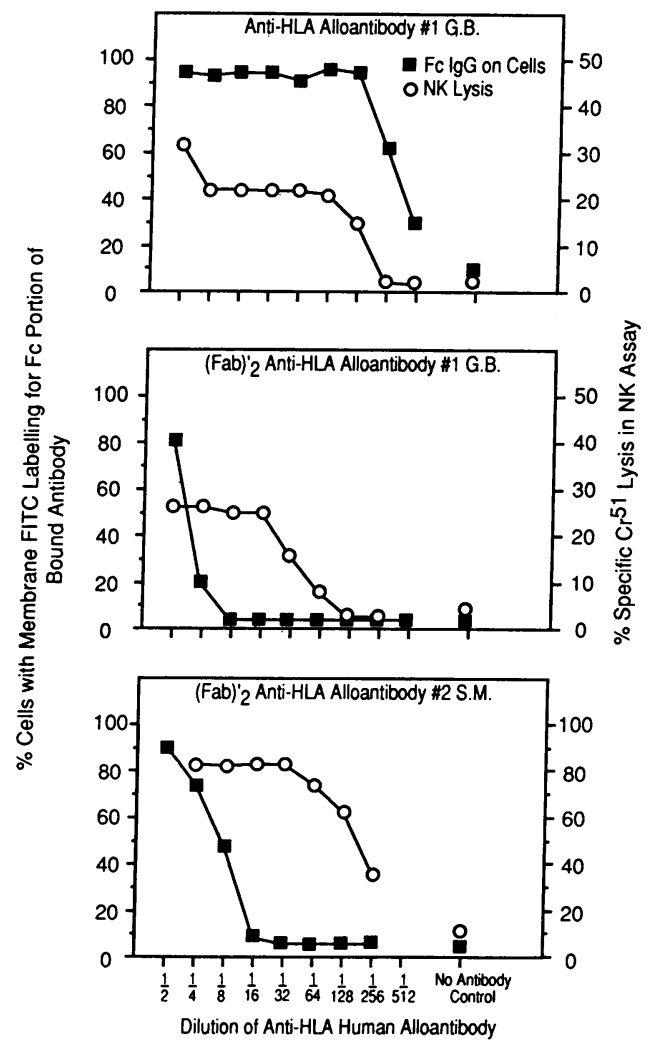

Figure $3 .{ }^{51} \mathrm{Cr}$ labeled lymphoblastoid cell lines were pretreated with varying dilutions of either intact (top panel) or $\mathrm{F}\left(\mathrm{ab}^{\prime}\right)_{2}$ fragments (middle and lower panels) of anti-HLA alloantibodies, washed and then subjected to NK lysis. The purity of $F\left(a b^{\prime}\right)_{2}$ fragments is illustrated by indirect immunofluorescence using FITC $F\left(a^{\prime}\right)_{2}$ goat antihuman IgG ( $\mathrm{Fc}$ specific) (flow cytometry) to determine if antibody bound to target cells contained the $\mathrm{Fc}$ portion of the IgG molecule. For example, in the middle panel, no intact Fc containing IgG alloantibody could be detected at 1:8 dilution of the $F\left(a b^{\prime}\right)_{2}$ anti-HLA, No. 1, G.B. JY was the target cell used in the top two panels while Daudi was used in the lower panel. 

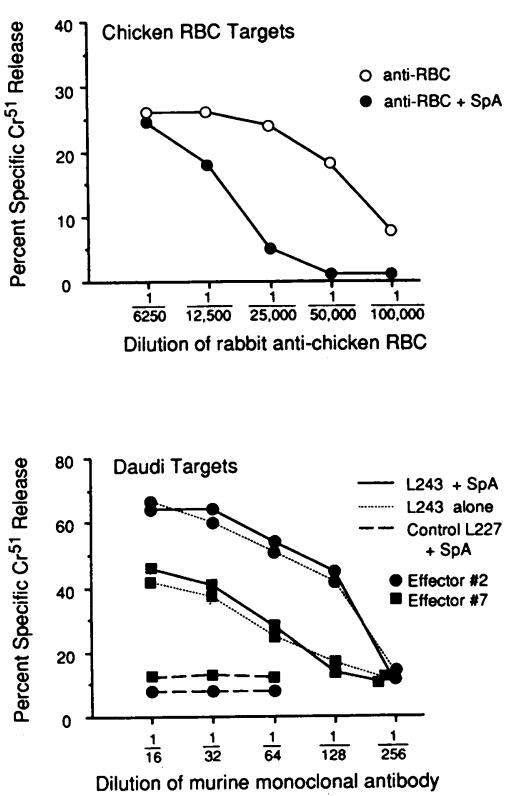

Figure 4. SpA binding to Fc region of membrane bound antibodyeffect on ADCC (upper panel) and NK lysis (lower panel). ${ }^{51} \mathrm{Cr}$ labeled target cells were incubated with 25 lambda of appropriate dilution of antibody at $4^{\circ} \mathrm{C}$ for $30 \mathrm{~min}$, washed and then reincubated with $50 \mu \mathrm{g}$ of $\mathrm{SpA}$ at $4^{\circ} \mathrm{C}$ for $30 \mathrm{~min}$. Target cells were washed after the SpA incubation before the ADCC and NK assay. Data in this figure are with an effector to target ratio of 25:1. L227 was used as a control for SpA as it is an anti-DR mouse monoclonal that binds very efficiently to SpA but does not enhance NK activity. L243 at 1:16 dilutions had $0.2 \mu \mathrm{g}$ of antibody in 25 lambda.

spite using (Fab) ${ }_{2}^{\prime}$ anti-HLA alloantibody and in dilutions with no contaminating intact anti-HLA antibody. Thirdly, SpA did not inhibit the enhanced NK lysis mediated by anti-HLA monoclonals despite demonstrating avid binding of SpA to the monoclonal antibody. In agreement with previous studies, under similar conditions SpA inhibited an ADCC-mediated lysis of $C R B C$ with rabbit anti-CRBC, which has a higher affinity for FcIgG receptors than murine IgG (Fig. 2) (31-33). ADCC as a rule is more sensitive than indirect immunofluorescence in detecting antibody binding to targets. Yet, in all our experiments demonstrating enhanced NK lysis, monoclonal and alloantibody binding to target cells could be detected by indirect immunofluorescence by at least two dilutions more than the dilutions needed to demonstrate enhanced NK lysis (Fig. 3). Such observations also argue against ADCC in our studies.

Thus far, from the data we have presented there is suggestive evidence to indicate that target cells were rendered more susceptible to postbinding lysis because anti-HLA antibodies may have masked or blocked relevant epitopes on the HLA molecules, which are responsible for inhibiting processes that induce NK activity after NK cells bind to target cells. Masking of relevant HLA epitopes would best explain why all anti-HLA mouse monoclonal antibodies, e.g., anti-HLA-BW6 or antiHLA-DR (L227, 2.06, and IVA 12) will not render target cells more susceptible to postbinding lysis and will best explain why all five alloantibodies (with broad anti-HLA reactivity) led to enhanced NK lysis. Similarly, a masking effect would best explain the need to use larger quantities of antibody to obtain optimal enhanced NK lysis. Membrane modulation of the HLA molecule seems unlikely as we observed no shedding, internalization, or capping of these membrane molecules (Table V).

There are, however, other factors that are responsible for imparting resistance to tumor cells. This may explain why

certain solid tumor targets (e.g., SK-MEL-1) could not be lysed by NK cells despite masking or blocking HLA cell membrane determinants. SK-MEL-1 was lysed very efficiently (and independently of HLA masking) by lymphokine activated killer cells (data not shown). It is possible that membrane glycoproteins other than HLA antigens may impart NK resistance to certain solid tumor cell lines as has been suggested before.

In conclusion, the present data indicate that MHC gene products can protect lymphoid and certain solid tumor cell lines from NK mediated lysis. These data extend previous observations (4-7) by (a) using a more direct approach to mask HLA antigens, thus circumventing the possibility of altered expression of other non-HLA molecules on variant target cell lines contributing to enhanced NK susceptibility and $(b)$ demonstrating the protective role of beta-2-microglobulin and class II molecules. As is evident from Table V, HLA molecules do not affect binding of tumor targets to NK effectors. However, poor expression of HLA molecules leads to more efficient postbinding target cell lysis. This mechanism is contrary to tumor cell lysis induced by cytotoxic $\mathrm{T}$ lymphocytes, where increased expression of MHC gene products leads to more efficient recognition and lysis $(35,36)$. Since tumor cells often

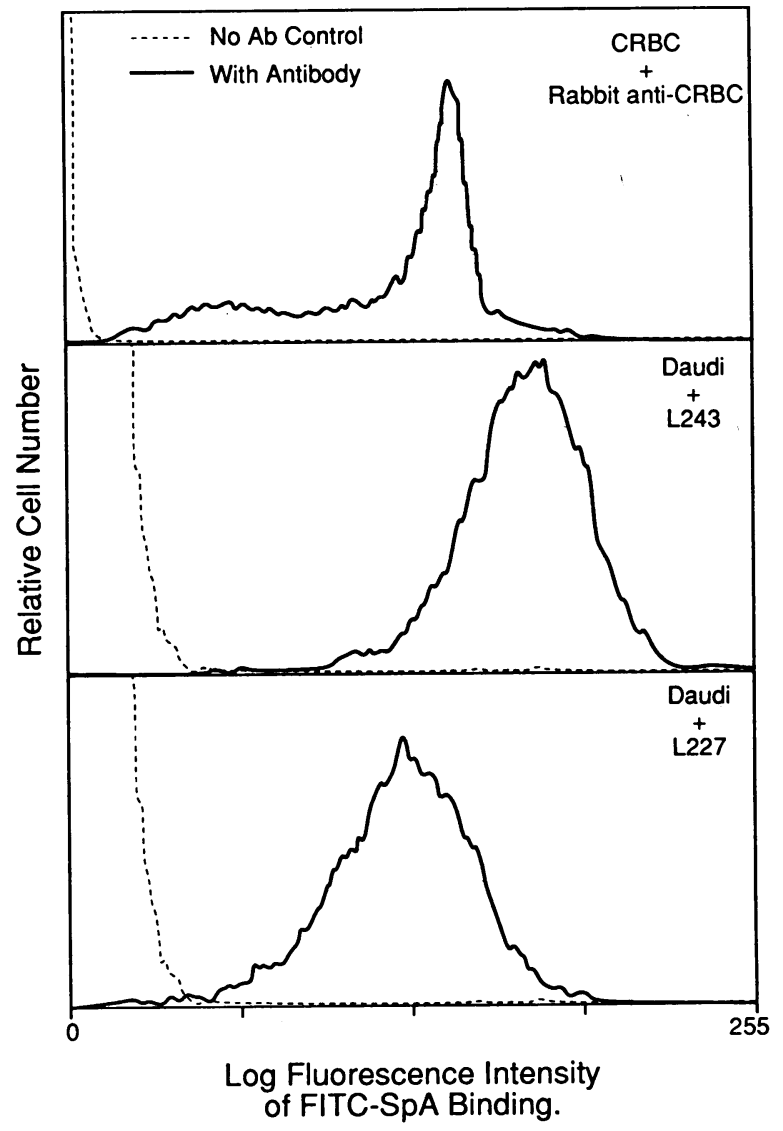

Figure 5. Comparison of binding avidity of SpA to mouse monoclonals (L243, L227) and rabbit anti-CRBC. Target cells (either Daudi or CRBC) were incubated at $4^{\circ} \mathrm{C}$ for $30 \mathrm{~min}$ with appropriate dilution and quantity of antibody as used in experiments illustrated in Fig. 4. After the incubation, cells were washed and then reincubated with $50 \mu \mathrm{g}$ of FITC labeled SpA at $4^{\circ} \mathrm{C}$ for $30 \mathrm{~min}$. Target cells were rewashed before the ADCC and NK assay. Cells were examined by flow cytometry. Background control fluorescence (dashed lines) was determined by incubating cells with FITC SpA but with no antibody. 
show alterations in their expression of MHC gene products, it is possible that reduced expression may allow tumor cells to escape detection by cytotoxic $\mathrm{T}$ lymphocytes as has been previously proposed (37). NK effectors may have evolved to prevent the growth or expansion of tumor cells that have escaped $T$ cell recognition, a hypothesis that has been put forward by Karre and his colleagues (4).

\section{Acknowledgments}

The authors wish to thank Ann E. Wright and Terry A. Pritchard for their expert technical assistance and Deborah P. Bush for her excellent secretarial assistance in the preparation of this paper. This work was funded by the Department of Renal Services and the Hiatt Fund.

\section{References}

1. Herberman, R. B., J. Y. Djeu, D. H. Kay, J. R. Ortaldo, C. Ricardi, G. D. Bonnard, H. T. Holden, R. Faguani, A. Santoni, and P. Puccetti. 1979. Natural killer cells: characteristics and regulation of activity. Immunol. Rev. 44:43-70.

2. Savary, C. A., and E. Lotzova. 1986. Phylogeny and ontogeny of NK cells. In Immunobiology of Natural Killer Cells. E. Lotzova and R. B. Herberman, editors. CRC Press, Boca Raton, FL. 46-61.

3. Herberman, R. B., C. W. Reynolds, and J. R. Ortaldo. 1986. Mechanism of cytotoxicity by natural killer cells. Annu. Rev. Immunol. 4:651-680.

4. Karre, K., H. G. Ljunggren, G. Piontek, and R. Kiessling. 1986. Selective rejection of $\mathbf{H - 2}$ deficient lymphoma variants suggests alternative immune defense strategy. Nature (Lond.). 319:675-678.

5. Ljunggren, H. G., and K. Karre. 1985. Host resistance directed selectively against $\mathrm{H}-2$ deficient lymphoma variants. J. Exp. Med. 162:1745-1759.

6. Harel-Bellan, A., A. Quillet, C. Marchiol, R. DeMars, T. Tursz, and D. Fradelizi. 1986. Natural killer susceptibility of human cells may be regulated by genes in the HLA region of chromosome 6. Proc. Natl. Acad. Sci. USA. 83:5688-5692.

7. Storkus, W. J., D. N. Howell, R. D. Salter, J. R. Dawson, and P. Cresswell. 1987. NK susceptibility varies inversely with target cell Class I HLA expression. J. Immunol. 138:1657-1659.

8. Sowada, Y., B. Fohring, T. Shenk, and K. Raska. 1985. Tumorigenicity of adenovirus-transformed cells: region EIA of adenovirus 12 confers resistance to natural killer cells. Virology. 147:413-421.

9. Cook, J., T. Walker, A. Lewis, H. Ruley, R. Graham, and S. Pidler. 1986. Expression of the adenovirus EIA oncogene during cell transformation is sufficient to induce susceptibility to lysis by host inflammatory cells. Proc. Natl. Acad. Sci. USA. 83:6965-6968.

10. Gorelik, E., Y. Gunji, and R. Herberman. 1988. H-2 antigen expression and sensitivity of BL6 melanoma cells to natural killer cell cytotoxicity. J. Immunol. 140:2096-2102.

11. Dennert, G., C. Landou, E. M. Lord, D. W. Bahler, and J. G. Frelinger. 1988. Lysis of a lung carcinoma by poly $1-C$-induced natural killer cells is independent of the expression of Class I histocompatibility antigens. J. Immunol. 140:2472-2475.

12. Brodsky, F. M., and P. Parham. 1982. Monomorphic antiHLA-A,B,C monoclonal antibodies detecting molecular subunits and combinatorial determinants. J. Immunol. 128:129-135.

13. Brodsky, F. M., P. Parham, and W. F. Bodmer. 1980. Monoclonal antibodies to HLA-D́Rw determinants. Tissue Ant. 16:30-48.

14. Brodsky, F. M. 1984. A matrix approach to human Class II HLA antigens: reactions of four monoclonal antibodies with the product of nine haplotypes. Immunogenetics. 19:179-194.

15. Lampson, L. A., and R. Levy. 1980. Two populations of Ia-like molecules on a human B cell line. J. Immunol. 125:293-299.

16. Capra, J. D., and R. C. Giles. 1985. Specificity of monoclonal antibodies directed against human and murine Class II histocompatibility antigens as analyzed by binding to HLA-deletion mutant cell lines. Hum. Immunol. 12:191-211.
17. Charron, D. J., and H. O. McDevitt. 1979. Analysis of HLA-D region-associated molecules with monoclonal antibody. 1979. Proc. Natl. Acad. Sci. USA. 76:6567-6571.

18. Yonish-Rouach, E., G. Cordier, J. Cohen, C. Vincent, and J. Brochier. 1983. Analysis of human B cell membrane antigens by means of monoclonal antibodies. Protides Biol. Fluids. 30:487-490.

19. Lobo, P. I., C. Spencer, J. Gorman, and G. Pirsch. 1981. Critical appraisal of complement dependent microlymphocytotoxicity assay for detecting donor-specific alloantibody. Hum. Immunol. 2:55-64.

20. Perlmann, P., H. Perlmann, and H. Wigzell. 1972. Lymphocyte mediated cytotoxicity in vitro. Induction and inhibition by humoral antibody and nature of effector cells. Transp. Rev. 13:91-114.

21. Ortaldo, J. R., C. Woodhouse, A. C. Morgan, R. B. Herberman, D. A. Cheresh, and R. Reisfeld. 1987. Analysis of effector cells in human ADCC with murine monoclonal antibodies. 1987. J. Immunol. 138:3566-3572.

22. Lanier, L. L., J. H. Phillips, J. Hackett, M. Tutt, and V. Kumar. 1986. Natural killer cells: definition of a cell type rather than a function. J. Immunol. 137:2735-2739.

23. Lobo, P. I. 1984. Human B lymphocytes with receptors for sheep erythrocytes. Their relevance in techniques to obtain $T$ cells depleted of mature B cells. Immunol. Methods. 123:2861-2869.

24. Lobo, P. I., J. B. Winfield, A. Craig, and F. B. Westervelt. 1977. Utility of protease digested human lymphocytes for the detection of lymphocyte reactive alloantibodies by indirect immunofluorescence. Transplàntation. 23:16-21.

25. Grimm, E., and B. Bonavida. 1979. Mechanism of cell mediated cytotoxicity at the single cell level. J. Immunol. 123:2861-2869.

26. Henkart, P., P. Willard, C. Reynolds, and M. Menkart. 1984. Cytolytic activity of purified cytoplasmic granules from cytotoxic rat LGL tumors. J. Exp. Med. 160:75-93.

27. Horwitz, D. A., and P. I. Lobo. 1975. Characterization of two populations of human lymphocytes bearing easily detectable surface immunoglobulin. J. Clin. Invest. 56:1464-1472.

28. Parham, P. 1983. On the fragmentation of monoclonal IgG1, IgG2a, and IgG2b from BALB/c mice. J. Immunol. 131:2895-2902.

29. Oi, V. T., and L. A. Herzenberg. 1979. Localization of murine Ig-1b, and Ig-1a (IgG2a) allotypic determinants detected by monoclonal antibodies. Mol. Immunol. 16:1005.

30. Lamoyi, E., and A. Nisonoff. 1983. Preparation of $\left(\mathrm{Fab}^{\prime}\right) 2$ fragments from mouse IgG of various subclasses. J. Immunol. Methods. 56:235-243.

31. Kay, D. H., G. D. Bonnard, W. H. West, and R. B. Herbermann. 1977. A functional comparison of human $\mathrm{Fc}$ receptor-bearing lymphocytes active in natural cytotoxicity and antibody dependent cellular cytotoxicity. J. Immunol. 118:2058-2066.

32. Rosenblatt, J., P. M. Zelzer, J. Portaro, and R. C. Seegar. 1977. Inhibition of antibody-dependent cellular cytotoxicity by Protein A from staphylococcus aureus. J. Immunol. 118:981-985.

33. Ghetie, V., G. Mota, M. Dobre-Ghetie, M. Laky, A. Olinescu, S. Dima, I. Moraru, and J. Sjoquist. 1986. Modulation of IgG effector functions by a monovalent fragment of staphylococcal protein A. Mol. Immunol: 23:377-384.

34. Korubluth, J., B. Spear, S. S. Raab, and D. B. Wilson. 1985. Evidence for the role of Class I and II HLA antigens in the lytic function of a cloned line of human natural killer cells. J. Immunol. 134:728-735.

35. Wallich, R., N. Bulbuc, G. J. Hemmerling, S. Katzau, M. Feldman, and S. Segal. 1985. Abrogation of metastatic properties of tumor cells by de novo expression of $\mathrm{H}-2 \mathrm{~K}$ antigens following $\mathrm{H}-2$ gene transfection. Nature (Lond.). 315:301-305.

36. Tanaka, K., K. J. Isselbacher, G. Khoury, and G. Jay. 1985. Reversal of oncogenesis by the expression of a major histocompatibility complex Class I gene. Science (Wash. DC). 228:26-30.

37. Doherty, P., B. Knowles, and P. I. Wettstein. 1984. Immunological surveillance of tumors in the context of major histocompatibility complex restriction of T cell function. Adv. Cancer Res. 42:1-31. 